\title{
Interdependent preferences and policy stances in mainstream economics
}

\author{
FRANÇOIS CLAVEAU \\ EIPE, Erasmus University Rotterdam
}

\begin{abstract}
An individual's preferences are interdependent when they can be influenced by the behaviour of other agents. This paper analyzes the internal dynamics of an approach in contemporary economics allowing for interdependent preferences, the extended utility approach (EUA), which presents itself as a mild reform of neoclassical economics. I contend that this approach succeeds in broadening the policy perspectives of mainstream economics by challenging neoclassical policy stances. However, this success comes with a limitation: the EUA is unable to supply new consensual policy stances as alternatives to the challenged ones. The reason for this limitation is that the EUA opens the possibility of a wide variety of specifications for the utility function, and policy conclusions are sensitive to the details of these specifications.
\end{abstract}

Keywords: interdependent preferences, extended utility function, neoclassical economics, Pareto efficiency, welfare analysis, policy recommendations

JEL Classification: B40, D01, D03, D60, E13

The face of mainstream economics has changed dramatically in the last three decades (Colander, et al. 2004; Colander 2005; Davis 2006; Davis 2008). This development has come neither from a single breakthrough nor as a consequence of a revolutionary outcry. In fact, many of the changes have resulted from attempts by economists to meet the following reformist challenge: "what can you explain if you accept all of the standard assumptions except one?" (Ackerman 1997, 656) It is

AUTHOR's NoTE: I would like to thank two anonymous referees of this journal, as well as Luis Mireles-Flores, J. C. R. Rowley, Francisco Álvarez-Cuadrado, Koen Swinkels, Caterina Marchionni, and the participants of the EIPE PhD/ReMa Seminar on the 20th of October 2008, for many helpful comments on previous drafts of this text. For financial support, I am grateful to the Fond Québécois de la Recherche sur la Société et la Culture (FQRSC), the Social Science and Humanities Research Council of Canada (SSHRC), and to the Netherlands Organization for International Cooperation in Higher Education (Nuffic). 
mainly by the cumulative impact of rounds of this game that mainstream economic theory has moved on.

This paper focuses on one axis of research stemming from this reformist challenge. This axis tries to address a common objection to neoclassical economics regarding its extremely narrow account of the social character of humans. Critics have relentlessly said that individuals are intertwined in a much more complicated manner than neoclassical economics is ready to accept. To remedy this defect, some mainstream scholars have accepted to expand the social character of economic agents in the theory by endowing them with interdependent preferences. In a standard choice model, social interactions could be allowed through three channels: external constraints, information (beliefs), and preferences. The research covered here refers only to the work employing the third channel. ${ }^{1}$

The concept of interdependent preferences can be given a simple, intuitive definition: preferences that are influenced by the behaviour of other agents. For instance, in the context of demand functions, Robert A. Pollak defines them as "preferences which depend on other people's consumption" (Pollak 1976, 309). More generally, preferences can be influenced by many types of behaviour by peers far beyond strict consumption. Staying in the realm of traditional subjects in economics, we may underline the role of interpersonal effects on labour supply decisions: if my fellow workers accept enthusiastically to work overtime, I may be more receptive to this idea as well. Being more eclectic, we could also reflect on the consequences of culture on nutritional habits and physical activity. ${ }^{2}$

From the vast panorama of approaches in economics on the concept of interdependent preferences, I will focus on the internal dynamics of one approach: the extended utility approach (EUA). Basically, this approach involves extending the number of variables in the utility function while keeping the entirety of the other 'standard assumptions'. Given that a major motivation behind the EUA is to offer new policy insights, I investigate how the approach fares on this dimension. I contend that it succeeds in challenging neoclassical policy stances but that it does not supply consensual alternatives. Looking forward into how the EUA could overcome this limitation, I find that it will hit on

\footnotetext{
${ }^{1}$ There is also research in mainstream economics on the two other channels, e.g., Bikhchandani, et al. 1998, on information; Postlewaite 1998, on additional constraints. ${ }^{2}$ Note that nothing forces one to see interdependent preferences in such examples. They could be due to the information or the constraint channels.
} 
even greater problems if more empirical evidence is brought to bear on the specifications of the extended utility functions.

More precisely, the paper defends four claims. First, the EUA is a typical exercise in the reformist challenge; it keeps the whole of the neoclassical framework except one assumption, i.e., independent preferences. To substantiate this assertion, I present in the first section what I consider to be the four pillars of neoclassical economics. I also use this section to list some of the policy stances typical of neoclassical economics. In the second section, I describe the general framework of the EUA and explain its relation to the neoclassical framework thus bringing home my first claim; the proponents of the EUA are indeed playing the reformist game. The second claim is that theoretical results of EUA often conflict with the typical policy stances of neoclassical economics, and is defended in the third section of this article. In the fourth section, I turn to my third claim: the EUA is not equipped to supply new consensual policy stances, because it lacks the resources to discriminate between competing specifications of interdependent preferences. In fact, the EUA currently proposes a cacophony of policy recommendations. This result is in agreement with the conventional wisdom of economists. Scholars have warned for decades that allowing for more factors to be included in the utility function would make it possible to reach any desired conclusion, thus given the flavour of adhocness to the whole exercise. In the fifth section, I speculate on what the proponents of the EUA could do next. I explore the possibility that they widen the range of empirical evidence considered in order to choose the specification of their extended utility function. The fourth claim I defend, thus, is that moving in this direction will force the EUA to reconsider its adherence to (at least) one of the four pillars of the neoclassical framework, namely: Pareto efficiency. Empirical studies on interdependent preferences readily disconfirm the neoclassical assumption-necessary for conventional welfare analysis-that individual choice tracks individual welfare.

\section{NEOCLASSICAL ECONOMICS}

Since I contend that the EUA, while allowing for interdependent preferences, tries to remain as close as possible to the neoclassical framework, I start by defining what I mean by neoclassical economics. I take Gary Becker's characterization of the "economic approach" as stating the core elements of the neoclassical research program: "The 
combined assumptions of maximizing behavior, market equilibrium, and stable preferences, used relentlessly and unflinchingly, form the heart of the economic approach as I see it" (Becker 1976, 5). This quote delineates three pillars of the positive part of neoclassical economics: (a) given preferences, (b) maximization and (c) equilibrium as the outcome of the interaction of optimizing agents.

It is crucial to note that the core of neoclassical economics also has a normative component in the concept of Pareto efficiency. Due to "economics' self-conception as a positive science" (Davis 2005, 195), economists tend to forget this component when they attempt a characterization of their core theoretical elements. However, Pareto efficiency, with "its role as the only policy recommendation generally accepted in economics" (Davis 2005: 195), is central to theoretical and applied neoclassical economics.

The fundamental role of a shared normative criterion for neoclassical economics-Pareto efficiency being the current one-can be appreciated if we go back to what is sometimes called the ordinal revolution in utility theory. Before the 1930s, many economists were routinely assuming the possibility of interpersonal comparisons of utility, i.e., that one's change in utility can be compared to the change in utility of another agent. In his Essay on the nature and significance of economic science, Lionel Robbins forcefully attacked the postulate of interpersonal comparability of satisfaction: "It is a comparison which necessarily falls outside the scope of any positive science" (Robbins 1949 [1932], 139). Robbins was quite aware of the consequences of his argument for welfare economics. Referring to a vibrant reply by Roy Harrod, ${ }^{3}$ Robbins asserted "that economics as a science [can] say nothing by way of prescription" (Robbins 1938, 637).

At the same time, Harold Hotelling (1938), Nicholas Kaldor (1939) and John Hicks (1939) entered the debate drawing heavily on the feeling of a methodological crisis among economists. In his Foundations of welfare economics, considering his task to be "mainly one of synthesis", Hicks proposed "to set out briefly and simply the main lines of the new welfare economics" (Hicks 1939, 698). This new foundation, he claimed,

\footnotetext{
${ }^{3}$ Harrod wrote: "If the incomparability of utility to different individuals is strictly pressed, not only are the prescriptions of the welfare school ruled out, but all prescriptions whatever. The economist as an adviser is completely stultified, and, unless his speculations be regarded as of paramount aesthetic value, he had better be suppressed completely" (Harrod 1938, 397). In line with Melville (1939), he then argued that the postulate should still be used even if it places us at the border of science.
} 
was rendered necessary by Robbins's criticism since "economic positivism might easily become an excuse for the shirking of live issues, very conducive to the euthanasia of our science" (Hicks 1939, 697). He then proposed the well-known Pareto efficiency and the compensation criterion $^{4}$ as the central concepts of new welfare economics. Economics was saved from euthanasia.

One of the central achievements of neoclassical economics in the last century is that the Pareto criterion, in conjunction with the standard model of the three pillars, has led to the ossification of a set of standard policy recommendations. This set is an integral part of the contemporary culture of economics. Today, students of neoclassical economics, apart from struggling with the intricacies of model building and equilibrium definition, learn this set of governmental 'good practices'. Lecturers of microeconomic courses commonly engage in comparative statics while asking: 'in what state agents are better-off?' With this training, students soon master the basic policy stances which include, for instance: aim at higher output, respect consumer sovereignty, prefer cash transfers to in-kind ones, and increase the cost of undesirable behaviour.

I should be clear: I do not claim that economics is monolithic, or that every economist endorses these prescriptions. The different surveys of economists give the picture of a community with a varying degree of homogeneity in beliefs depending on the issues (e.g., Kearl, et al. 1979; Frey, et al. 1984; Alston, et al. 1992; Fuller and Geide-Stevenson 2003). Furthermore, I do not believe that such broad policy stances are necessary implications of working with the four core neoclassical pillars defined above. Indeed, as we will see, the EUA works with the four pillars as well, but reaches different normative implications. My point is rather that the training of neoclassical economists makes these policy prescriptions salient. The usual interpretations of their models are in line with these recommendations and make economists often fall back on such stances when they face a policy issue. Let me take in turn each policy stance of the short list given above so as to illustrate how these prescriptions are made salient by receiving training in neoclassical economics.

\footnotetext{
${ }^{4}$ The compensation criterion soon lost its popularity when its theoretical defects were revealed (Gorman 1955). Pareto efficiency was left as the only consensual normative criterion of neoclassical economics.
} 
'Growth is good' is a basic normative conclusion of the neoclassical culture. In general, higher output translates into a weakening of the budget constraint of agents, hence in a higher potential utility. A famous variant of this argument is due to Robert Lucas (1987, chapter 3). For him, the promotion of economic growth is far more important than policies aimed at stabilizing the business cycle, since the "potential gains from improved stabilization policies are on the order of hundredths of a percent of consumption" (Lucas 2003, 11). Lucas maintains that this sharp normative conclusion is the result of the progress of the neoclassical research program: "we are able to form a much sharper quantitative view of the potential of changes in policy to improve peoples' lives than was possible a generation ago" (Lucas 2003, 12).

The typical fondness of economists for the idea that 'the agent is the best judge of her interest' comes from the fact that textbook models are premised on this idea. The function maximized under constraints by the agent is at the same time the measure of her welfare. If she was not able to reach a higher utility given the constraints, no one else could do it for her. Hence follows the normative notion of consumer sovereignty: it is good that the agent be left to choose by herself. ${ }^{5}$ Since consumer sovereignty is embedded in the assumptions of the neoclassical models, it is no wonder that a high proportion of economists endorse this view.

The idea that 'transfers should be in cash rather than in kind' is related to consumer sovereignty. Money can be allocated by the individual according to her preferences while goods are far less

\footnotetext{
${ }^{5}$ Jack Vromen pointed out to me that 'consumer sovereignty' is also (and probably more often) used to refer to the thesis that consumers, through their purchasing decisions, are the ones selecting what gets to be produced. In this case, consumer sovereignty is a descriptive concept, i.e., the thesis may be false. If one accepts the descriptive concept, the normative notion can be rephrased as 'it is good that consumers be the ones orienting production'. But one can also think that consumer sovereignty is false as a description but keep it as an ideal to strive for. In the case of neoclassical economics, the normative notion of consumer sovereignty is supported by the belief that 'the individual knows best' without any need to endorse the descriptive statement.

The reader should also note that 'consumer sovereignty' is also used by some authors to refer directly to the idea that 'the individual knows best', e.g., "the standard principle of consumer sovereignty according to which every individual is the best judge of his own interests" (Fleurbaey 2008). I will not conflate the two meanings because, if economists seem to endorse the normative notion of consumer sovereignty because they believe that 'the individual knows best', it is also possible to reject the latter claim and still endorse consumer sovereignty. For instance, Robert Sugden (2004) recognizes that individual choices are sometimes at odds with their interest, but maintains that the individual should be free to choose anyway.
} 
fungible. If the government gives food stamps for instance, it presumes that individuals are in need of edible goods. By transferring money instead, the government leaves it to the individual to allocate her resources to what is more conducive to her welfare. Some opinion surveys asked economists if they agree with the following statement: "Cash payments increase the welfare of recipients to a greater degree than do transfers-in-kind of equal cash value". ${ }^{6}$ In 1976, only $8 \%$ of respondents disagreed with the statement-68\% agreed and 24\% agreed with provisos (Kearl, et al. 1979). The same pattern showed up again in 1990, when disagreement with the statement rose to $14 \%$ of respondents-62\% agreed and 24\% agreed with provisos (Alston, et al. 1992, 206).

Neoclassical economics is also a discourse about incentives, about decision makers weighing the costs and benefits of the alternatives they face. If asked what strategy could help curb some undesirable behaviour, the typical response of an economist is 'to increase the expected cost of the behaviour'. For instance, the criminality rate should respond to the probability of being caught and to the length of the jail sentences. It is by playing on the expected returns of unwelcome behaviour that the State can control to some extent these 'deviations'.

EUA scholars challenge these four neoclassical policy stances. In fact, one of the main motivations behind the work in the EUA seems to be the broadening of the policy views in economics. According to most proponents of this approach, taking into account social interactions has an important impact on the normative conclusions of the analysis. Before showing how the EUA weakens the standard policy views, let me elaborate more on what the EUA actually is.

\section{EXTENDED UTILITY APPROACH AND INTERDEPENDENT PREFERENCES}

The general framework of the EUA is well illustrated by the work of Gary Becker (1996) and of Becker and Kevin Murphy (2000). In this section, I will use their model and their peculiar vocabulary to characterize the EUA as applied to interdependent preferences.

The focus on Becker's formulation does not mean that he is a sort of "leader" of the extended utility school. There is no such school: economists working with the EUA in the study of social interactions share a theoretical approach but they do not belong to any

\footnotetext{
${ }^{6}$ Unfortunately, I was not able to find survey questions that test the popularity of the other policy stances.
} 
institutionalized school. Some of them would not even recognize themselves as members of a common approach. I use the Beckerian formulation as a depiction of the EUA, simply because it summarizes well the relationship between this approach and textbook economics.

In Social economics, Becker seems to have changed his mind on what are "the traditional foundations of [...] the economic approach to behavior" (Becker and Murphy 2000, 5). He cites only "utility maximization and equilibrium in the behavior of groups" while omitting the "stable preferences" component of his 1976 definition. One should not be misguided by this omission. Becker and Murphy still accept the neoclassical dictum of fixed preferences, but they give to it a somewhat odd twist. The evolution of Becker's definition of the economic approach is probably an indication that the authors are conscious that what they call 'stable preferences' would be viewed as highly unstable by most economists.

The key distinction between the usual neoclassical approach and that of Becker is his use of the concept of 'extended utility functions'. These are "utility functions that remained the "same" over time and are the "same" for different individuals" (Becker 1996, 6) even though the social context changes. In short, whatever happens in the social environment, Becker wants his objective function to stay intact, only the values of the variables will change. The innovation is thus to extend "the definition of individual preferences to include personal habits and addictions, peer pressure, parental influences on the tastes of children, advertising, love and sympathy, and other neglected behavior" (Becker 1996, 4).

From the standpoint of the extended utility function, the standard functions postulated by neoclassical economists are "subutility functions of goods [that] 'shift' over time in response to advertising, addictions, and other behavior" (Becker 1996, 6). The preference relation of an agent between, say, rock and jazz may appear to change if we focus on the subutility function, but it is simply because of an omittedvariables bias. To remove the anomaly, we need to include in the utility function, for instance, the musical habits of friends. The extended utility function can then be written as:

$$
U=U(x ; P, S)
$$

where $x$ is a vector of typical variables generically labelled as 'goods', $P$ is "personal capital"-potentially including past consumption and 
other personal characteristics-and $S$ "represents social influences on utility through stocks of 'social capital'” (Becker and Murphy 2000, 9). ${ }^{7}$

Since we are interested in interdependent preferences, let me keep the $P$ in the background and focus on $S$. In a pure Beckerian style, the analogy between this 'social capital' and the usual physical capital is further explored by claiming, for instance, that the stock $S$ is subject to some depreciation rate (which could be 100\%). The stock inherited from the past may strongly affect present choices of $x$ if it depreciates relatively slowly. For example, if one element of $x$, say $x_{i}$, and $S$ happen to be strong complements, the individual's choice of value for $x_{i}$ will increase with inherited $S .{ }^{8}$ The concept of social capital in the extended utility function is broadly defined as "the effect of others' choice on own utility" (Becker 1996, 12). This definition places little constraints on what the modeller actually puts for $S$.

Students of neoclassical economics will feel at home with the EUA: the maximization-equilibrium framework remains, and even the stability of preferences-if appropriately understood-is left untouched. Moreover, by its loyalty to fixed preferences (stability of the extended utility function), the EUA makes it possible to keep the normative component of the neoclassical core (this condition was stated as early as: Kemp 1955, 218). If the preference ordering changed with the context, different contexts would be incommensurable. But the extended utility function gives the stable metric necessary for the use of Pareto optimality; in models of the EUA, we can tell when the agent is 'betteroff' in the exact same way as in conventional models. ${ }^{9}$ For Becker, it is

\footnotetext{
${ }^{7}$ The extended utility function has to be distinguished from meta-rankings defined as "rankings of preference rankings" (Sen 1977, 337; in fact, Becker explicitly rejects Sen's view; see Becker 1996, 17). Most importantly in the present context, meta-rankings do not generally allow a neat use of Pareto optimality as is the case for the extended utility function (Voorhoeve 2006).

${ }^{8}$ To make this relation more concrete, suppose that $x$ is hours spent watching a given television series during summer vacation and $S$ is the hours spent by colleagues watching the same series last month. If one wants to participate in lunchtime discussions, one may choose to sit more hours in front of a screen given that coworkers are known to be fans of such series. In Becker's jargon, hours spent by coworkers watching television is a complement to one's time 'spent' in front of the box.

${ }^{9}$ It may not be altogether clear to the reader that, since Pareto efficiency uses the individuals' own rankings of outcomes to determine which situation is socially better, these subjective rankings need to be stable across states of the world that we wish to rank. To make this requirement clearer, let me build a toy example where agent's $i$ preference map depends on the context. Let $\boldsymbol{P}_{\mathrm{J}}$ denote the strict preference relation in context J. If $i$ happens to be in context $X$ where meals are usually served with potatoes, the conformist $i$ will prefer potatoes to rice $\left(p \boldsymbol{P}_{\mathrm{X}} r\right)$. If the agent is thrown in context $\mathrm{Y}$ where rice is the standard side dish, $i$ will prefer rice to potatoes $\left(r \boldsymbol{P}_{\mathrm{Y}} p\right)$. Can we say
} 
'business as usual' in normative economics: "If the relevant utility function for welfare analysis includes personal and social capital, the effect on utility of advertising and public policy can be evaluated without any ambiguity" (Becker 1996, 20).

Beyond the retention of the Pareto criterion, the EUA is also following the neoclassical customs in using the vocabulary of externalities to characterize interpersonal effects. In the EUA, when an agent acts, she does not take into account the welfare effect of her action on the preferences of others. There is thus a potential wedge between the private valuation of an action and its social value. Akerlof's language is representative of this application of the notion of 'externality' to discussions of interdependent preferences:

Except under rare circumstances, such interactions produce externalities. These externalities typically slow down movements toward socially beneficial equilibria but in the most extreme cases they will create long-run low-level equilibrium traps that are far from socially optimal (Akerlof 1997, 1005). ${ }^{10}$

Scholars associated to the EUA go on to say that the presence of these externalities opens the door to beneficial interventions by governments. To be sure, there is sharp disagreement among economists about the extent of the inefficiencies created by interpersonal effects and the promise of governmental interventions-I will return to this debate later. Beyond this controversy, the proponents of the EUA agree on what counts as an appropriate justification of

something about the Pareto ranking of the bi-dimensional outcome X-potatoes relative to Y-rice? In other words, can we say something like ' $i$ prefers eating potatoes in context $\mathrm{X}$ than having rice in context $\mathrm{Y}$ '? If we take i's 'partial' preferences-where partial means only defined over the meal consumed-as the standard, the two outcomes are incommensurable since the choice of metric $\left(\boldsymbol{P}_{\mathrm{X}}\right.$ or $\left.\boldsymbol{P}_{\mathrm{Y}}\right)$ is arbitrary. If we take $i$ 's preferences to mean ' $i$ 's preferences in context $X$ ' $\left(\boldsymbol{P}_{\mathrm{X}}\right)$ outcome $\mathrm{X}$-potatoes is Pareto superior. However, the inverse is true if we take ' $i$ 's preferences in context $Y$ ' $\left(\boldsymbol{P}_{\mathrm{Y}}\right)$ as the relevant ordering.

For the advocates of the EUA, the way out of this dead-end is to consider the "total preference map" (Kemp 1955). Instead of defining the preferences only over goods consumed (e.g., $r$ and $p$ ), the agent is now assumed to rank states of the world defined as the conjunction of goods consumed and context. In the example above, there are four states in the stable preference ordering. From the assumed choices of $i$, we already know the preferred meal given the context $[(p, \mathrm{X}) \boldsymbol{P}(r, \mathrm{X})$ and $(r, \mathrm{Y}) \boldsymbol{P}(p, \mathrm{Y})]$. Now, we can also rank states of the world stemming from different contexts (the most interesting binary relation should be the one between $(p, \mathrm{X})$ and $(r, \mathrm{Y})$, that is: Does the agent prefer to eat potatoes among potato-eaters over the alternative of eating rice among rice-consumers?

${ }^{10}$ On “positional externalities” see also Frank 2005; 2008. 
public intervention. The model discriminates between optimal and suboptimal outcomes. If we believe that a low-level equilibrium might prevail, intervention aiming at diverting the system to a better outcome should be considered.

Scholars of the EUA accept integrally the methodological principles of normative neoclassical economics. The shared understanding of the appropriate justification of public policies-correcting suboptimal outcome due to externalities-structures the debate between neoclassical economists. From the point of view of public policy discussions, the modelling ritual of economists appears as a speculative game about why some stylized social outcome may or may not be optimal.

We can distinguish two waves in this game. In a first wave, users of the extended utility function argued that accounting for interdependent preferences may change a lot, if not most, of the standard policy prescriptions stemming from neoclassical economics. In a second wave, the increase in the number of extended utility models resulted in a competition among models of the EUA, each leading to different, often contradictory, policy conclusions.

\section{THE FIRST WAVE, CHALLENGING HARD-WIRED POLICY STANCES}

Since policy guidance is such an important goal in economics, a fresh look at normative implications is probably the most important result of the EUA. In this section, I will illustrate some of the normative claims that the EUA raises against the standard neoclassical models. It has been argued that hard-wired policy prescriptions in neoclassical economics hinge on the assumption of independent preferences.

The most cited result of the EUA questions the idea that economic growth necessarily leads to improved welfare. The germs of this scepticism can be traced back to James Duesenberry's relative-income hypothesis (1949). Duesenberry rejected the usual specification of the utility function where only an agent's own consumption and own leisure appear. He argued that a measure of the consumption norm (the $S$ in the case above) had to figure in this function. According to him, agents do not derive satisfaction from their absolute level of consumption but from their consumption relative to the consumption of their fellows. Duesenberry proposed to define the income term in the indirect utility function as the ratio of own income to average group income. The new stance toward growth follows from this specification of the utility 
function since economic growth with a stable social distribution of income leaves relative income unchanged. If one's income grows at the same rate than GDP per capita, the proportional increase of the two terms in the relative income variable will leave satisfaction unchanged.

The literature drawing on the relative-income hypothesis is now extremely voluminous (see Clark, et al. 2008). Starting with Richard Easterlin's seminal paper (1974), this hypothesis is widely cited to explain why the strong economic growth of Western countries in the second half of the twentieth century has not generally been accompanied by increased happiness. To be sure, even if we accept the strong claim that higher average real income does not imply more consumption satisfaction, "that does not mean that economic growth becomes a matter of social indifference" (Frank 1985, 36). It could well be that economic growth brings other benefits such as:

[...] the link between the length of life and (aggregate) income; the link between the ability to withstand foreign aggression and economic activity; the ability to attract migrants when income levels are relatively high; and some status utility benefit to a country as a whole from having high income compared to other countries (Clark, et al. 2008, 124).

Nevertheless, the relative-income hypothesis implies that the neoclassical argument for growth is misguided. In the logic of the relative-income hypothesis, it is not because people can consume more that growth should be welcomed.

Despite its popularity, the relative-income hypothesis is arguably covering only a small part of the social interactions relevant to economists. Since it was first intended to explain the relationship between income and the savings rate, it only posits a connection between one's consumption level and the consumption levels of agents in one's reference group. Therefore it does not address the interpersonal impact of different types of consumption goods, since all goods are lumped into a unique value. To improve on this crude picture of the dynamics of comparison in which consumers are engaged, some authors argue that it is necessary to distinguish between conspicuous and non-conspicuous goods. ${ }^{11}$ Some goods-such as houses, cars, and clothes-generate satisfaction partly by comparing one's bundle to the

\footnotetext{
${ }_{11}$ See Frank 1985; 1997; 2007; and see Hirsch 1976, for the related notion of 'positional goods'; also see McAdams 1992, for a discussion of the two notions.
} 
others. They are said to enter the utility function in a relative form. Other goods-like insurance, time with friends, and rest-are almost only desired for their absolute (versus relative) attributes. A vast amount of resources is spent on conspicuous goods simply to 'keep up with the Joneses'. However, agents will be better-off if the conspicuous expenditures of everybody were kept low and the resources were reallocated to non-conspicuous goods. Hence, according to these scholars, the problem is not with economic growth per se, but with growth primarily channelled to conspicuous consumption.

The conspicuous good theory forces a reconsideration of the normative concept of consumer sovereignty which is at the heart of the neoclassical culture-as described in the first section of this article. Typically, economists believe that "each person [should be] free to get what she wants [... since she] is the best or proper judge of her own well-being" (Sugden 2004, 1016). Here, the externalities created by conspicuous consumption make the systemic effect of individual decisions unappealing: "Roughly speaking, the problem is that we work too many hours, save too little, and spend too much of our incomes on goods that confer little additional satisfaction when all have more of them" (Frank 2007, 103). Consequently, welfare economics prescribes that individuals should not get what they want. There is room for the government to limit the wastes due to competitive consumption. Since we are in presence of externalities, taxes are welcomed to realign the price mechanism. The literature thus offers various proposals to implement taxes on conspicuous goods or on consumption in general, e.g., Robert Frank's progressive consumption tax (2007, chapter 11). ${ }^{12}$

\footnotetext{
${ }^{12}$ It might sound surprising to many that I have put Robert H. Frank as a user (or a supporter) of the EUA. But let me give the microphone to Frank so that he can explain how he sees his approach:
}

Frank: [...] I think that I am much closer to the neoclassical approach than most people in the new economics and psychology movement.

[...]

Interviewer: Do you see your work as trying to incorporate as much as you possibly can within the rational choice model?

Frank: Yes, that's the way I see it.

$[\ldots]$

Once you put in a taste for these things, then it's just like a taste for pushpins, it's the same model as before; it's constrained maximization [...] If you want to say that someone has a taste for doing the right thing, alright, you put a taste in for that, and there's a taste for own income and consumption.

[...]

I still think my intellectual capital is more with the old static maximization model (Interview with Robert H. Frank; in Colander, et al. 2004, 116, 117-118, 125). 
In addition, the recommendation that governmental transfers should be in money instead of in kind rested on the acceptance of consumer sovereignty. Now that agents may not allocate their resources in the best way, in-kind transfers targeted to non-conspicuous goods may be preferable. In short, this part of the literature on interdependent preferences, which is limited to interpersonal effects through status concern, does away with some of the central normative propositions that a student of neoclassical economics would be encouraged to accept.

When I write that the welfare conclusion of the research on conspicuous goods is that individuals should not get what they want, it is important to see how this conclusion is in agreement with a long tradition in economics related to collective action problems. The conclusion does not come from the rejection of the belief that the 'individual knows best' because the agents are still making the optimal choice given the decision context. What happens is that one's choice affects the decision context of the other agents, i.e., we have externalities.

The argument for conspicuous goods is thus strictly analogous to the one for an arms race between two nations: each nation allocates an important part of its resources to military armament because the other nation does the same; they will both be better-off if they could make a binding agreement to limit military expenditures (Frank 2005, 138). What is peculiar to the literature on conspicuous goods is that, suddenly, a great proportion of individual actions typically considered private are now said to follow the logic of collective action problems. These private actions have a collective dimension because they are factored in the extended utility function of each agent.

Another branch of the literature on interdependent preferences, the 'identity' models (e.g., Akerlof 1997; Akerlof and Kranton 2000; 2002; 2005) challenges yet a different dimension of standard policy prescriptions in economics. In these models, the $S$ in the extended utility function contains a vector representing the actions of other agents and a sub-function defining one's "identity or self-image" (Akerlof and Kranton 2000, 719). Identity depends on multiple factors including one's assigned social category (e.g., male or female). Associated to the social categories, there are prescriptions indicating "the behavior appropriate for people in different social categories in different situations" (Akerlof and Kranton 2000, 718). To illustrate their notion of social prescription, George Akerlof and Rachel Kranton give the 
following cliché: "the ideal man is male, muscular, and should never wear a dress, except perhaps on Halloween" (Akerlof and Kranton 2000, 718). Then, they use this payoff function in simple static games to offer explanations for phenomena like "gender discrimination in the labor market, the economics of poverty and social exclusion, and the household division of labor" (Akerlof and Kranton 2000, 718).

Equipped with this peculiar specification of the extended utility function, Akerlof and Kranton are up to challenge the view that the fundamental strategy behind public interventions is to change the 'price ratios' of different actions. If you want less crime, an economist would typically tell you to increase the cost of being caught. Similarly, if you want people to get more education, increase the benefits or lower the costs of education. However, if an agent's action is highly affected by the way she defines her identity, then changes in 'prices' may not have a great impact on her choice once her identity is fixed. One conclusion is that identity should be changed. Changing identities is not an easy task for public officials, but it points to quite different means than the standard strategy focusing on incentives.

Even free higher education will not bring a large proportion of children from low-income families into universities if their social background makes them think that college studies are not for them. Stricter criminal penalties will not have the promised impact if criminal behaviour is driven by neighbours' behaviours (Glaeser, et al. 1996). Neighbourhoods with a good mix of social categories may be more effective. In sum, "in important special cases the incorporation of [...] social factors into rational choice analysis results in behavior that more closely corresponds to the intuition of sociologists than of economists" (Akerlof 1997, 1006). Hence, the prescriptions derived from the models will also be closer to the ones of non-economists.

\section{THE SECOND WAVE, DISCORDING VOICES INSIDE THE EUA}

My goal in the previous section was to show how some results of the EUA challenge basic neoclassical policy recommendations, and to make clear how the usual results in welfare economics rested on a problematic premise, namely independent preferences. While the EUA has shown that standard prescriptions should be reassessed, it does not follow that the normative conclusions of any particular model accounting for interpersonal effects are better grounded. In fact, it comes with no surprise that, depending on the chosen structure of the 
interdependence, a model could produce radically divergent policy prescriptions.

Larry Samuelson (2006) illustrates this 'specification sensitivity' by considering different assumptions on the form of the relative consumption effects. In fact, his models pertain only to the class where the interdependence is strictly instrumental, i.e., the interdependence is not written in the utility function as is the case of the EUA but it comes from additional constraints to the optimization problem of agents (such as presented by Postlewaite 1998). Samuelson thus recognizes that "the set of possible sources of relative consumption effects is much richer" (Samuelson 2006, 264). Nevertheless, he concludes that policy prescriptions are highly contingent on the chosen assumptions:

These examples indicate that once behavioral interdependencies are allowed into our economic model, even such straightforward questions as whether distortionary taxes improve or dissipate welfare are open to question. The answer depends upon the nature of the interdependencies and the market in which these effects find expression. Without further study, none of our conventional welfare conclusions can be taken for granted (Samuelson 2006, 263).

The success of the reformists' promise to offer a better guide for governmental interventions is thus far from guaranteed. It hinges on a justificatory procedure for the choice of assumptions. The modeller will need to present good reasons for why she selects these "fine details of utility functions and market interactions" (Samuelson 2006, 261), instead of the countless other potential combinations, if she wants her policy prescriptions to be credible. Unfortunately, no common justificatory procedure exists among members of the EUA.

When the interdependence effect takes the form of an additional constraint imposed on agents (as in the cases considered by Samuelson), we may have the hope that studying the institutional structure of the relevant 'market' will tell us how to specify our model. This strategy will not do for the EUA. When the interdependence effect is located in the utility function (i.e., in the internal valuation mechanism of agents) looking at the working of the market will not be sufficient. There is a fundamental problem of underdetermination of the model by data here. One can think of different specifications of the extended utility function that give the same predictions for the market behaviour of agents (i.e., how individual demand will react to a change in prices or income) but, and this is the important point, have different normative implications, 
e.g., how the well-being of agents will be modified by a change in prices or income.

A range of specifications of Duesenberry's utility theory (see the previous section) entertains this relation with standard utility theory (with independent preferences). To make this point clear with the simplest example possible, let me define $Y_{i}$ as the income of agent $i$ and $\hat{Y}$ as the average income of agents in i's reference group (national GDP per capita for instance). In standard utility theory, the simplest, oneperiod specification of the indirect utility function would be $U(Y)$, where $U$ is strictly increasing. Given such a function, a manna increasing the income of all agents will make everybody better-off; the primitive intuition for 'growth is good'. With Duesenberry's utility theory, the simplest specification would be the strictly increasing function $U(Y / \hat{Y})$. In this case, the manna leaves at best all agents indifferent. It may even make some agents worse-off. ${ }^{13}$ This example illustrates why Heinz Holländer maintains that "[i]n the realm of welfare theory [...] the standard approach and Duesenberry's approach often lead to diametrically opposed results so that it is of great importance which one is used in evaluating policies" (Holländer 2001, 230).

In the same paper, Holländer specifies the range of conditions under which the behavioural implications of both theories are identical and concludes that "[i]t is not to be expected [...] that observed behavior will enable us to discriminate empirically between the two approaches" (Holländer 2001, 232-233). ${ }^{14}$ If the required conditions apply, we face the underdetermination problem: we have two theories indistinguishable from the perspective of standard empirical tests (i.e., how well a model predicts behavioural responses to changes in prices and income), but

\footnotetext{
${ }^{13}$ It all depends on the form taken by the manna increase. It is easy to verify that if each agent receives the same amount of manna independently of the agent's initial income $\left(Y_{i}+\mathrm{m}\right.$, where $\mathrm{m}$ is the same for all $\left.i\right)$, the ones with an income above the mean will be worse-off, while the ones below the mean will benefit from the change. Alternatively, if the income of all increases proportionally $\left(\mathrm{m} \cdot Y_{i}\right)$, the manna changes nothing to welfare. To see how sensitive the welfare conclusions are to the specification of $U(\cdot)$, the reader can verify that the results are almost the opposite if the utility function is $U\left(Y_{i}-\hat{Y}\right)$. Now, an additive manna has no effect on welfare, while the ones below the mean suffer from a manna increase proportional to income.

${ }^{14}$ It will lead me too far from my main argument if I was to explain the technical conditions needed for Duesenberry's utility theory to empirically mimic the standard theory, but I can still list them. First, the extended utility function-including as variables leisure (l), a consumption vector (x), and a vector of reference consumption (a)-needs to be weakly separable in (l, x). Second, "commodity preferences must be homothetic, and [third] the marginal value of leisure must be directly proportional to commodity consumption" (Holländer 2001, 230). For the explanation of the conditions, I refer the interested reader to Holländer's 2001 paper.
} 
leading to divergent policy stances. To be sure, it is also possible that the conditions are not met in the case of the contest between the relative-income hypothesis and the standard utility theory, and that one of the two theories is actually better at predicting behavioural responses. But the point should be clear by now. By allowing for more terms in the utility function, the EUA has created a far more flexible tool which means that it is easier to reach contradictory policy conclusions based on different particular models, but harder to tell which model should be believed. The hard task for proponents of the EUA is thus to legitimize the choice of a given specification.

The lack of shared criteria among proponents of the EUA to justify the form taken by the interpersonal effects makes the policy debate obviously value-driven. At the present state of the research efforts, it seems hard to reject that the competing models using an extended utility are simply reflecting the modellers' divergent prejudices. The charge of Becker and Murphy against Frank's normative conclusions is a perfect illustration of this 'dialogue of the deaf'. Frank is drawing farreaching implications from the presence of interdependent preferences. For instance, in his recent book, he argues that interpersonal effects, combined with the rise of inequality in the United States, profoundly harm the middle class (Frank 2007). In response to this kind of assertion, Becker and Murphy emit doubts that indeed interdependent preferences produce inefficiencies: "Strong, and often unreasonable, assumptions about the role of marital and other pricing lie behind criticisms by Frank and others" (Becker and Murphy 2000, 124). Accordingly, they tend to focus on models where "status can be purchased in a competitive marketplace" or on particular institutional setups where "women [are] fully [compensated] for the utility gain to their husbands or other companions from their wearing high heels" (Becker and Murphy 2000, 123). As one would expect, these models lead to efficient outcomes.

When they accept 'distorted' pricing due to interdependent preferences, Becker and Murphy are tempted to emphasize that it could well come to correct some otherwise inefficient outcome (e.g., underinvestment in risky activities such as entrepreneurial or scientific careers): "Competition for status might even raise efficiency compared with the situation when utility does not depend on status" (Becker and Murphy 2000, 124). Since no criteria is presented to select among competing models, these comments are pure speculations. In fact, 
Becker and Murphy recognize candidly that their position stems from their prejudice: "To put this differently, critics stress the 'rat race' aspects of the competition for status, whereas we believe in the American dream that competition to 'get ahead' makes a society function better, not worse" (Becker and Murphy 2000, 125). Who will they convince which is not already on their side?

Let me sum up. We have seen that the EUA has considerably reduced the support for the neoclassical set of standard policy recommendations. However, the EUA, after this phase, has failed to construct a new set of typical recommendations as a replacement. This failure is due to a structural problem of the approach. The EUA is an extremely flexible apparatus and there is no shared criteria among modellers on the actual way to use it, that is, on the way the interdependence is to be modelled. We thus see a proliferation of models, each presenting a particular recipe, and leading to divergent normative implications. One cannot help but concluding, with Daniel Zizzo, that, "in practice, the endogeneity is simply modelled by introducing fuzzy variables in the utility (or meta-utility) function, that are then allowed to change in ad hoc ways" (Zizzo 2003, 874).

For many decades, the conventional wisdom of economists was able to police the practice of model building: the variables allowed in the utility function were not subject to negotiation. The fear was that opening the utility function to other factors meant, in fact, opening Pandora's box. The above discussion supports the common apprehension of economists. The neoclassical framework could deliver a standard set of policy recommendations as long as the rule of using only independent preferences was generally followed. Once interdependent preferences are allowed on stage, the neoclassical framework cannot generate a harmonious prescriptive stance anymore. At least, it will not be able to do so until it finds a procedure to discriminate between all the competing models.

Given the diversity of extended utility models in the literature today, it becomes blatant to the observer how much the normative conclusions one reaches depend on 'arbitrary' assumptions about the form of the interdependence. This disillusion also affects the status of the standard neoclassical model since it is now only one among many models in the literature. The postulate of the standard model on the form of the social interactions, namely that there is no interdependence, is as weakly grounded as the numerous other possibilities. The EUA has not only 
dethroned the set of standard policy recommendations, it has made it far more difficult to build new consensual normative stances.

\section{CAREFUL EMPIRICAL GROUNDING AS A WAY OUT?}

To dispel the feeling of arbitrariness surrounding their models, EUA scholars will have to argue more persuasively for the specific utility function that they choose. Once we "appreciate that behavioral assumptions [...] tend to rule out some policy ideas and favor others" (Berg 2003, 424), we need to be far more careful in specifying the interdependence structure than modellers in the EUA typically are. Since no specification can be ruled out a priori, empirical studies investigating the structure of the interpersonal effects would have to be at the forefront of the conversation. We have seen in the last section that using behavioural responses to changes in prices and income-the official empirical procedure in neoclassical economics to infer the utility function-would most likely not be enough to discriminate between specifications implying contradictory policy conclusions. The additional desirable evidence that I have in mind would have to go beyond such a procedure. I am thinking of jointly using a set of carefully-designed experiments, subjective surveys, neurological data, evolutionary hypotheses, ${ }^{15}$ and the like.

I am far from suggesting that it is something novel to claim that the specification of the extended utility function should be more empirically informed. Scholars participating in the now highly-influential economics and psychology movement have been already making the same point. The idea is clearly stated by Samuel Bowles:

The need for empirical grounding of assumptions is nowhere clearer than in the analysis of individual behavior, where the process of enriching the conventional assumptions about cognition and preferences can easily descend into ad hoc explanation unless disciplined by reference to facts about what real people do (Bowles 2004, 16).

\footnotetext{
${ }^{15}$ The qualifier 'empirical' is probably less fitting for evolutionary hypotheses, but one has to keep in mind that, due to theory-ladenness, all the other alleged empirical types of evidence are also conditioned by background conceptions. The theoretical understanding is only more conspicuous for evolutionary hypotheses. When I argue that EUA scholars will need to be more empirical, I do not mean the naïve thesis that they should face the barren facts. I intend to say that the attitude should be one of active gathering of data from a diversity of sources.
} 
The idea is also expressed by some members of the EUA that I have mentioned above. For instance, Robert Frank talks in an interview of the same problem of ad-hocness (Colander, et al. 2004, 117), and includes other types of evidence in his work, like evolutionary hypotheses (e.g., Frank 2005). Likewise, scholars drawing on the relative-income hypothesis have been supporting their ideas with happiness surveys already for some decades.

Is it just a matter of bringing all the evidence together to select the 'right' extended utility function and then derive the correct policy conclusions from this empirically-based specification? If this possibility comes true, it would be a terrific achievement for the EUA. Unfortunately, it appears that, if EUA scholars were attentive to all evidence instead of picking and choosing the evidence supporting their preferred specifications, the EUA would hit a wall. More specifically, I maintain that a basic presumption of the EUA will not survive the move toward a deep acquaintance with all available evidence. This approach-one variation of the reformist challenge discussed in the introduction-was erected on the belief that interdependent preferences could be allowed in the analysis while keeping intact the neoclassical framework (of fixed preferences, maximization, equilibrium, and Pareto efficiency). In fact, available empirical evidence on interdependent preferences readily disconfirms a core requirement of the neoclassical framework permitting the link between an agent's choice and its welfare. With this link broken, the Pareto criterion is adrift. Hence, if my analysis is correct, the EUA, in its attempt to justify its assumptions, has to face strong evidence against its conventional use of Pareto efficiency.

The utility function behind neoclassical welfare analysis is twofold. First, it is the objective function determining the economic choices of an agent. The story supporting the model is that the agent chooses, in the feasible set, the bundle giving her the highest utility level. In positive analysis, the utility function is thus at the centre of the choice mechanism. Second, the utility function also tells us the welfare of the agent. A feasible bundle associated to a higher utility will not only be chosen over a competing bundle, it will also make the agent better-off. Thus, the utility function enables the ranking of alternatives in view of the Pareto criterion. The combination of the choice and the welfare dimensions of the utility function sustains the neoclassical economists' idea that, given the constraints, the agent will make the welfaremaximizing choice for himself. 
Many behavioural economists argue against this amalgamation of the choice and welfare dimensions. It seems that, in many contexts, "people do not appear to do what is best for themselves" (Loewenstein and Ubel 2008, 1795). If we wish to keep the concept of the utility function, growing evidence points to the possibility that choices are guided by one function, "decision utility", while satisfaction arises from a different function, "experience utility" (see Kahneman, et al. 1997; Kahneman and Sugden 2005; Kahneman and Krueger 2006). Put differently, it is as if agents, aiming at making the most satisfying choices, have a systematic tendency to mispredict the welfare effects of their choices. Why would they have this tendency?

Many scholars claim that one central source of this choice bias is that some dimensions of alternatives, the extrinsic attributes, are overweighted in the decision process (e.g., Bowles 1998, 90-91; Frey and Stutzer 2004; and 2006; Hargreaves Heap 2005, 201-202). In general, the intrinsic attributes are rewards stemming directly from an action, for instance, satisfaction derived from meeting friends. The action is pursued because it delivers this satisfaction. Conversely, extrinsic attributes "serve people's goals for material possessions, fame, status or prestige" (Frey and Stutzer 2004, 3). Actions chosen because of their extrinsic attributes are not valued for themselves but only as means to another end where the satisfaction lies. It is not necessary here to develop the psychological theory supporting this distinction (e.g., Deci and Ryan 2000). However, it is important to note that extrinsic attributes are the ones driving the race for social status, a phenomenon taking a central place in the EUA. Saying that extrinsic attributes are overweighted in the decision process is akin to assert that the benefits of higher status are overweighted.

Hence, behavioural studies on the effects of social interactions tell us that a dimension of these interactions-the one associated to statusseeking-is one source of the disjunction between decision utility and experience utility. If we take this disjunction seriously, the neoclassical welfare analysis is undermined, since this analysis assumes that the model of individual choices can also be used to evaluate individual welfare. With the insight of behavioural economics, it appears that explaining choices with an extended utility model should be sharply distinguished from evaluating the efficiency of the outcome.

I have three comments before closing. First, the divergence between behavioural economics and the EUA shows how much the notion of 
interdependent preferences is treated differently depending on one's starting point. If the researcher begins the enquiry by wondering how to add some variables in the utility function to account for our folk understanding of social interdependence, she is led in the direction of the EUA. Alternatively, if one starts by studying how an agent's ex ante and ex post valuations relate to each other for different types of choice, she comes to emphasize that our concern for relative standing makes us ultimately dissatisfied with our chosen option. The understanding that EUA scholars have of interdependent preferences thus hinges on the fact that they are responding to the reformist challenge.

Second, and more importantly for the present paper, the divergence between the results emphasized in this section and the presumption of the EUA demonstrates that the EUA has to be transformed by its confrontation with empirical evidence on the form of the interdependence. It is a chimera to think that, provided we have postulated an extended utility function, "public policy can be evaluated without any ambiguity" (Becker 1996, 20).

Third, to situate this section in the rest of my argument, I need to emphasize that the claim that decision utility cannot be used to evaluate welfare is logically independent from the developments in the EUA; the rift between decision and experience utility, provided it is serious, is devastating for standard welfare analysis regardless of the existence of the EUA. This result is however highly relevant when EUA scholars survey their options to pursue future research. Confronted with a wealth of incompatible policy conclusions, proponents of the EUA have to look for ways to circumvent this undesirable outcome. It is in this search that the relationship between status concerns and dissatisfaction is more likely to come to saliency. In other words, if no feeling of crisis was present, EUA scholars could go 'business as usual' and totally ignore other lines of research. In the present case, however, something must be done to redirect the EUA for the sake of policy relevance.

\section{CONCLUSION}

For more than a century, critics have complained about the "atomized, undersocialized conception of human action" (Granovetter 1985, 483) in neoclassical economics. According to them, the specification of homo economicus has led neoclassical economics to sketch a systematically biased image of social issues. Consequently, welfare economics has often been stigmatized as being nothing more than a jargon used by 
some scholars to advocate their particular prejudice. In the public arena, argue the critics, 'scientific welfare' is one political strategy among many: "Different social groups struggle for their alternative social programme utilizing an arsenal of weapons that includes, for many, their respective efficiency calculi" (Wolff 2006, 188).

At first, economists paid little attention to the criticism regarding their undersocialized agents. It is only recently that a wealth of scholars started to allow complex social interactions in their neoclassical models. The extended utility approach (EUA) is a highly popular way to extend economic models in the direction of interdependent preferences. I have first argued that the EUA, by focusing on the relaxation of only one assumption (independent preferences) in the standard modelling procedure, is a typical variation on the reformist challenge.

Even with this somewhat mild change, the EUA has comforted the opinion of the critics of standard welfare analysis; this analysis seems indeed to be systematically biased. Indeed, the second part of my argument was exactly that, once we allow for interdependent preferences, economists tend to conclude that "none of our conventional welfare conclusions can be taken for granted" (Samuelson 2006, 263). Moving on in my argument, I have maintained that an important shortcoming of the EUA is that, after blowing up the conventional set of governmental 'good practices', it is incapable of supplying new consensual policy stances.

To remedy this defect, it seems that a wider array of evidence should be used to discriminate between competing specifications of the extended utility function. The problem that I envisage for the EUA is that, if they attempt to account for all available evidence, they will meet other strands of research, strands that they could have completely disregarded otherwise. My last claim has been that this research dooms standard welfare analysis and, with it, the original project of the EUA. Welfare cannot be evaluated with the same function that is used to characterize choice.

This finding, presented in the last section, on the disjunction between choice and satisfaction is interesting regardless of the state of standard welfare analysis. But, in the past, other studies on the peculiarities of human satisfaction-e.g., Tibor Scitovsky's fascinating Joyless economy: an inquiry into human satisfaction and consumer dissatisfaction (1976) - have been totally ignored by the bulk of economists. The current episode is different because the results of the 
EUA have debunked conventional policy stances, and there is a clear feeling of crisis. I maintain that it is because EUA scholars are forcing economists to look at a wider array of evidence to discriminate between alternative specifications that the standard welfare analysis is more exposed today.

\section{REFERENCES}

Ackerman, Frank. 1997. Consumed in theory: alternative perspectives on the economics of consumption. Journal of Economic Issues, 31 (3): 651-664.

Akerlof, George A. 1997. Social distance and social decisions. Econometrica, 65 (5): 1005-1027.

Akerlof, George A., and Rachel E. Kranton. 2000. Economics and identity. Quarterly Journal of Economics, 115 (3): 715-753.

Akerlof, George A., and Rachel E. Kranton. 2002. Identity and schooling: some lessons for the economics of education. Journal of Economic Literature, 40 (4): 1167-1201.

Akerlof, George A., and Rachel E. Kranton. 2005. Identity and the economics of organizations. Journal of Economic Perspectives, 19 (1): 9-32.

Alston, Richard M., J. R. Kearl, and Michael B Vaughan. 1992. Is there a consensus among economists in the 1990's? American Economic Review, 82 (2): 203-209.

Becker, Gary S. 1976. The economic approach to human behavior. Chicago: University of Chicago Press.

Becker, Gary S. 1996. Accounting for tastes. Cambridge (MA): Harvard University Press.

Becker, Gary S., and Kevin M. Murphy. 2000. Social economics. Cambridge (MA): Harvard University Press.

Berg, Nathan. 2003. Normative behavioral economics. Journal of Socio-Economics, 32 (4): 411-427.

Bikhchandani, Sushil, David Hirshleifer, and Ivo Welch. 1998. Learning from the behavior of others: conformity, fads, and informational cascades. Journal of Economic Perspectives, 12 (3): 151-170.

Bowles, Samuel. 1998. Endogenous preferences: the cultural consequences of markets and other economic institutions. Journal of Economic Literature, 36 (1): 75-111.

Bowles, Samuel. 2004. Microeconomics: behavior, institutions and evolution. Princeton: Princeton University Press.

Clark, Andrew E., Paul Frijters, and Michael A. Shields. 2008. Relative income, happiness, and utility: an explanation for the Easterlin Paradox and other puzzles. Journal of Economic Literature, 46 (1): 95-144.

Colander, David. 2005. The future of economics: the appropriately educated in pursuit of the knowable. Cambridge Journal of Economics, 29 (6): 927-941.

Colander, David, Richard P. F. Holt, and John Barkley Rosser. 2004. The changing face of economics: conversations with cutting edge economists. Ann Arbor: University of Michigan Press.

Davis, John B. 2005. Robbins, textbooks, and the extreme value neutrality view. History of Political Economy, 37 (2): 191-196.

Davis, John B. 2006. The turn in economics: neoclassical dominance to mainstream pluralism? Journal of Institutional Economics, 2 (1): 1-20. 
Davis, John B. 2008. The turn in recent economics and return of orthodoxy. Cambridge Journal of Economics, 32 (3): 349-366.

Deci, Edward L., and Richard M. Ryan. 2000. The "what" and "why" of goal pursuits: human needs and the self-determination of behavior. Psychological Inquiry, 11 (4): 227-268.

Duesenberry, James Stemble. 1949. Income, saving and the theory of consumer behavior. Cambridge (MA): Harvard University Press.

Easterlin, Richard. 1974. Does economic growth improve the human lot? Some empirical evidence. In Nations and households in economic growth: essays in honor of Moses Abramovitz, eds. P. D. David, and M. Reder. New York: Academic Press, 89-125.

Fleurbaey, Marc. 2008. Ethics and economics. In The New Palgrave Dictionary of Economics, eds. Steven N. Durlauf, and Lawrence E. Blume. Basingstoke: Palgrave Macmillan. http://www.dictionaryofeconomics.com/article?id=pde2008_E000272 (accessed June 2009).

Frank, Robert H. 1985. Choosing the right pond: human behavior and the quest for status. New York: Oxford University Press.

Frank, Robert H. 1997. The frame of reference as a public good. Economic Journal, 107 (445): 1832-1847.

Frank, Robert H. 2005. Positional externalities cause large and preventable welfare losses. The American Economic Review, 95 (2): 137-141.

Frank, Robert H. 2007. Falling behind: how rising inequality harms the middle class. Berkeley (CA): University of California Press.

Frank, Robert H. 2008. Should public policy respond to positional externalities? Journal of Public Economics, 92 (8-9): 1777-1786.

Frey, Bruno S., Werner W. Pommerehne, Friedrich Schneider, and Guy Gilbert. 1984. Consensus and dissension among economists: an empirical inquiry. American Economic Review, 74 (5): 986-994.

Frey, Bruno S., and Alois Stutzer. 2004. Economic consequences of mispredicting utility. IERE Working Paper. Institute for Empirical Research in Economics, University of Zurich.

Frey, Bruno S., and Alois Stutzer. 2006. Mispredicting utility and the political process. In Behavioral public finance, eds. Edward J. McCaffery, and Joel Slemrod. New York: Russell Sage Foundation, 113-140.

Fuller, Dan, and Doris Geide-Stevenson. 2003. Consensus among economists: revisited. Journal of Economic Education, 34 (4): 369-387.

Glaeser, Edward L., Bruce Sacerdote, and José A. Scheinkman. 1996. Crime and social interactions. Quarterly Journal of Economics, 111 (2): 507-548.

Glaeser, Edward L., and José A. Scheinkman. 2003. Non-market interactions. In Advances in economics and econometrics: theory and applications, eds. M. Dewatripoint, L. P. Hansen, and S. Turnovsky. Cambridge: Cambridge University Press, 339-369.

Gorman, William M. 1955. The intransitivity of certain criteria used in welfare economics. Oxford Economic Papers, 7 (1): 25-34.

Granovetter, Mark. 1985. Economic action and social structure: the problem of embeddedness. American Journal of Sociology, 91 (3): 481-510. 
Hargreaves Heap, Shaun. 2006. Living in an affluent society: it is so 'more-ish'. In Real world economics: a post-autistic economics reader, ed. Edward Fullbrook. London: Anthem Press, 221-227.

Harrod, Roy F. 1938. Scope and method of economics. Economic Journal, 48 (191): 383412.

Hicks, John R. 1939. The foundations of welfare economics. Economic Journal, 49 (196): 696-712.

Hirsch, Fred. 1976. Social limits to growth. Cambridge (MA): Harvard University Press.

Holländer, Heinz. 2001. On the validity of utility statements: standard theory versus Duesenberry's. Journal of Economic Behavior \& Organization, 45 (3): 227-249.

Hotelling, Harold. 1938. The general welfare in relation to problems of taxation and of railway and utility rates. Econometrica, 6 (3): 242-269.

Kahneman, Daniel, and Alan B. Krueger. 2006. Developments in the measurement of subjective well-being. Journal of Economic Perspectives, 20 (1): 3-24.

Kahneman, Daniel, and Robert Sugden. 2005. Experienced utility as a standard of policy evaluation. Environmental and Resource Economics, 32 (1): 161-181.

Kahneman, Daniel, Peter P. Wakker, and Rakesh Sarin. 1997. Back to Bentham? Explorations of experienced utility. Quarterly Journal of Economics, 112 (2): 375405.

Kaldor, Nicholas. 1939. Welfare propositions of economics and interpersonal comparisons of utility. Economic Journal, 49 (195): 549-552.

Kearl, J. R., Clayne L. Pope, Gordon C. Whiting, and Larry T. Wimmer. 1979. A confusion of economists? American Economic Review, 69 (2): 28-37.

Kemp, Murray C. 1955. The efficiency of competition as an allocator of resources: II. External economies of consumption. The Canadian Journal of Economics and Political Science, 21 (2): 217-227.

Loewenstein, George and Peter A. Ubel. 2008. Hedonic adaptation and the role of decision and experience utility in public policy. Journal of Public Economics, 92 (89): 1795-1810.

Lucas, Robert E. Jr. 1987. Models of business cycles. New York: Basil Blackwell.

Lucas, Robert E. Jr. 2003. Macroeconomic priorities. American Economic Review, 93 (1): $1-14$.

McAdams, Richard H. 1992. Relative preferences. Yale Law Journal, 102 (1): 1-104.

Melville, L. G. 1939. Economic welfare. Economic Journal, 49 (195): 552-553.

Pollak, Robert A. 1976. Interdependent preferences. American Economic Review, 66 (3): 309-320.

Postlewaite, Andrew. 1998. The social basis of interdependent preferences. European Economic Review, 42: 779-800.

Robbins, Lionel. 1938. Interpersonal comparisons of utility: a comment. Economic Journal, 48 (192): 635-641.

Robbins, Lionel. 1949 [1932]. An essay on the nature and significance of economic science. London: Macmillan.

Samuelson, Larry. 2006. Perspective on the economy as an evolving complex system. In The economy as an evolving complex system, III, eds. Lawrence E. Blume, and Steven N. Durlauf. New York: Oxford University Press, 243-265.

Scitovsky, Tibor. 1976. The joyless economy: an inquiry into human satisfaction and consumer dissatisfaction. New York: Oxford University Press. 
Sen, Amartya K. 1977. Rational fools: a critique of the behavioral foundations of economic theory. Philosophy and Public Affairs, 6 (4): 317-344.

Sugden, Robert. 2004. The opportunity criterion: consumer sovereignty without the assumption of coherent preferences. American Economic Review, 94 (4): 10141033.

Voorhoeve, Alex. 2006. Preference change and interpersonal comparisons of welfare. Royal Institute of Philosophy Supplement, 81 (s59): 265-280.

Wolff, Richard. 2006. 'Efficiency': whose efficiency? In Real world economics: a postautistic economics reader, ed. Edward Fullbrook. London: Anthem Press, 185-188.

Zizzo, Daniel John. 2003. Empirical evidence on interdependent preferences: nature or nurture? Cambridge Journal of Economics, 27 (6): 867-880.

François Claveau is a $\mathrm{PhD}$ candidate at the Erasmus Institute for Philosophy and Economics, Erasmus University Rotterdam. His research focuses on the contributions of the new approaches in economics to the policy conversation and on the debate in economics over microfoundations in the context of causal reasoning for policy use.

Contact e-mail: <francois.claveau@mail.mcgill.ca> 